\title{
Motivational Interviewing
}

TRAINING R R S ARCH I I PLEMENTATION P RACTICE

\section{Developing Undergraduate Use of OARS \\ Skill Building for Senior Year Kinesiology Students}

\author{
John Coumbe-Lilley, PhD, ${ }^{1}$ Arin Weidner, BS ${ }^{1}$
}

\begin{abstract}
This article discusses course development, teaching, instructional methods and skills acquisition in motivational interviewing (MI) for kinesiology students completing a health coaching course in their senior year of undergraduate studies. The paper outlines how students 1) conducted a brief MI session, 2) applied open questions, affirmations, reflections and summaries (OARS) during a brief MI session and 3) identified the use and quality of OARS through the use of a range of learner centered practices (Weimer, 2002) including multi source feedback opportunities and approaches based on Kolb's (1984) experiential learning cycle. The authors provide ten recommendations for educators and trainers to help them develop their practice in the teaching, learning and assessment of $\mathrm{MI}$ in undergraduate students or new-to-MI learners.
\end{abstract}

Keywords

teaching, undergraduates, motivational interviewing

T he purpose of this paper is to share a method for instructing teaching and acquiring skills in motivational interviewing (MI) in the context of health coaching by undergraduate students in the field of kinesiology. Kinesiology is considered an applied health field by the author's institution. According to the American Kinesiology Association (2014):

\begin{abstract}
Kinesiology is an academic discipline which involves the study of physical activity and its impact on health, society, and quality of life. It includes, but is not limited to, such areas of study as exercise science, sports management, athletic training and sports medicine, socio-cultural analyses of sports, sport and exercise psychology, fitness leadership, physical educationteacher education, and pre-professional training for physical therapy, occupational therapy, medicine and other health related fields.
\end{abstract}

In 2013 the Department of Kinesiology and Nutrition at the University of Illinois at Chicago introduced a health coaching course for undergraduate students completing their last year of the Bachelors of Science degree in kinesiology. The majority of kinesiology students desire to work with people in fitness, health and sports contexts after completing their Bachelors of Science degree. Also, many students pursue further education in a range of health and medical careers like occupational therapy, nursing, physical therapy, dietetics, general medical practitioner, exercise physiologist and the like. The central component of this course was the teaching of the MI curriculum outlined in Miller and Rollnick (2013) listed on page 324 . We used this section to guide our work to ensure

\footnotetext{
${ }^{1}$ University of Illinois at Chicago, Department of Kinesiology \& Nutrition

The authors report no conflicts of interest.
}

Correspondence regarding this article should be addressed to: John Coumbe-Lilley PhD, University of Illinois at Chicago, Department of Kinesiology and Nutrition, 901 W. Roosevelt Road, Chicago, IL 60608. Email: jcoumb1@uic.edu students developed comfort, skill and effective OARS skills. We chose this focus because evidence indicated these foundational skills were critical for senior undergraduate learning and application prior to their graduation into the workforce, graduate school or other endeavors in related kinesiology fields (Miller \& Rollnick, 2013; Rollnick, Butler, Kinnersley, Gregory \& Mash, 2010; Resnicow, Dilorio, Soet, Borrelli, Hecht \& Ernst, 2002; Brodie \& Inoue, 2005; Antiss, 2009; Lundahl, Kunz, Brownell, Tollefson \& Burke, 2010).

In the following sections we discuss evidence for the inclusion and teaching of $\mathrm{Ml}$ for students in kinesiology related fields based on studies conducted at community, four year and graduate school levels of higher education. These studies focused on training of medical professionals using a variety of methods consistent with the approach described in this paper. Several studies in the field of dentistry have examined the training and uptake of $\mathrm{MI}$, as well as its applications. A randomized pilot trial using standardized patient method conducted by Koerber, Crawford and O'Connell (2003) demonstrated improvement of Brief Motivational Interviewing (BMI) applications by dental students exposed and trained in MI processes (engaging, focusing, evoking and planning) and counseling skills including the use of open questions, affirmations, reflections and summaries (OARS) versus those that were not. A later study by Croffoot, Bray, Black and Koerber (2010) using a community college student population examined the effects of coaching on dental hygienist uptake of MI learning and its use. A repeated measures approach was used showing improved application of MI by the students with coaching, specifically the use of open questions and summaries. Another study, by Hinz (2010), demonstrated via pre-posttest evaluation that the MI skills of third year dental students improved following several information sharing sessions.

Studies investigating the effects of teaching $\mathrm{MI}$ interventions in higher education have been conducted in medical schools. In a systematic review of literature by Soderlund, Madson, Rubak and Nilsen (2011), ten studies included for review demonstrated positive learning and application outcomes for general health care practitioners in the fundamental approaches and skills of MI. More specifically, Poirier and colleagues (2004) conducted a series of Ml content presentations through a 
sequenced, contextually appropriate action learning experience approach with medical students. Repeated measurement showed that medical students increased their knowledge and confidence in their capabilities to apply MI in clinical settings. Daeppen and colleagues (2012) conducted a randomized control design investigation comparing a control group who received basic communication skills training versus the experimental group that received an eight hour $\mathrm{Ml}$ training program. According to the authors, students in the $\mathrm{Ml}$ training program were found to utilize $\mathrm{Ml}$ applications including elements of OARS compared to the control group.

Finally, some literature exists showing the emergence of $\mathrm{Ml}$ into formalized curriculum offerings. For example, The School of Medicine at the University of Virginia introduced MI into the curriculum to develop counseling skills in first and third year students. Students that completed the curriculum reported a very strong need for MI skills and a strong sense of confidence in their capability to apply $\mathrm{MI}$ in general medical practice (White, Gazewood \& Mounsey, 2007). An MI curriculum was introduced to third year medical students at Yale Medical School, whose performance was evaluated during a standard patient assessment. Outcomes showed medical students could learn and apply MI skills proficiently (Haesler, Fortin, Pfeiffer, Walters \& Martino, 2011). Based on the evidence above, the inclusion of $\mathrm{MI}$ in formalized curriculum for students in kinesiology appears justified as an opportunity to develop the knowledge, spirit and approach of MI for their careers in the field.

In the section that follows we provide an explanation of how students were introduced to the use of core counseling skills (open questions, affirmations, reflections and summaries: OARS) with a client. For the purpose of this paper we concentrate exclusively on the learning of OARS. In later stages of the course, not documented in this paper, we focused on preparatory and mobilizing talk aligned with the desire, ability, reason, need and commitment statements (DARN-C) which are integral to $\mathrm{MI}$ (Miller \& Rollnick, 2013).

Next, we detail how students develop an understanding and comfort with the use of OARS in a learning situation enabled by a focus on three student learning outcomes. A $360^{\circ}$ feedback process, also known as Multi Source Feedback (MSF), promotes the provision of performance assessment feedback from a variety of sources concerning the behaviors and attitudes demonstrated by one or more individuals, engaging peers, tutors and participants in feedback activities (London \& Smither, 1995). The purpose of this approach is to raise self-awareness about personal performance levels and enable personal development and performance improvement Morgeson, Mumford and Campion (2005). MSF has been used in several medical student training contexts. Kogan, Holmboe and Hauer (2009) reviewed 85 citations of tools used with direct observation of an interaction between a patient and a medical student or used between trainees and tutors as part of the educational process. The analysis of this work showed that using a $360^{\circ}$ feedback process was one of fifty-five tools used to aid the learning and training of medical students. MSF through the use of systematic debriefing is often used following simulated and real clinical encounters. Studies using MSF in clinical education settings have shown the following benefits: transition from "novice" to "expert" practice (Matthews \& Veins, 1988); connection, sharing, learning and support (Babenko-Mould, Andrusyszyn \& Goldberg, 2004); learning integration and decompression following performance (Cantrell, 2008); enabling a holistic review of student performance (Mariani, Cantrell, Meakin, Prieto \& Drefuerst, 2013). In summary, MSF gave students and tutors the opportunity to engage openly and holistically about the practice and improvement of OARS.

\section{COURSE OVERVIEW}

The course was taught over a sixteen week semester using the training curriculum recommendations in Miller and Rollnick (2013) to guide instructional decision making. Chapter 24, "Learning Motivational Interviewing," outlines what individuals should learn about MI and makes recommendations for the way MI could be learned. The foundational content for the MI portion of the course was based on Miller and Rollnick (2013) and the two DVD series accompanying this text (Miller, Moyers \& Rollnick, 2013). The DVD series provides information, discussion, applications and case studies demonstrating the use of OARS in contexts common to students graduating from the field of kinesiology.

The introduction of this course into the curriculum and its learning processes and structures was led by a campus wide policy requiring all students to display the outcomes courses were intended to achieve. This paper is concerned only with $\mathrm{Ml}$ practice sessions performed after approximately twenty-four hours of structured teacher-learner interaction, over an eight week period of lecture. Discussion and interactive learning had taken place with the goal of developing Ml comprehension of what was termed MI-reliable, which is the measurable adherence of MI leading to a predictable treatment outcome and the measurable quality of $\mathrm{MI}$. Discussed in Miller and Rollnick (2009), this construct permitted us to measure and evaluate the student $\mathrm{Ml}$ practice that would come next. It enabled us the return to the quantifiable aspect of the work which helped students' understanding of the use of OARS in an MI session with a client.

We outline below how students achieved the following learning outcomes:

1. Conducted a brief MI session

2. Applied OARS during a brief MI interaction

3. Identified the use and quality of OARS during a brief MI conversation.

\section{SETTING UP THE BRIEF MI SESSION}

During the eight week period outlined above, students were exposed to $\mathrm{MI}$ content through integrated learning, peer exercises and video case study sessions. These learning approaches were supported by learner centered practices outlined in Weimer (2002) that focused on creating learner responsibility, a comfortable warm climate for students and instructors to communicate civilly and respectfully, and group and peer assessment exemplified by the MSF processes. In addition, we were guided in our teaching by a focus on developing critical thinking, defined as follows:

Criical thinking refers to the use of cognitive skills or strategies that increase the probability of a desirable outcome. Critical thinking is purposeful, reasoned, and goal-directed. It is the kind of thinking involved in solving problems, formulating inferences, calculating likelihoods, and making decisions. Critical thinkers use these skills appropriately, without prompting, and usually with conscious intent, in a variety of settings. That is, they are predisposed to think critically. When we think critically, we are evaluating the outcomes of our thought processes-how good a decision is or how well a problem is solved. (Halpern, 1999, p. 70)

We conducted several guided $\mathrm{Ml}$ analysis sessions using cases from the Miller and partners (2013) DVD series, deconstructing these interactions to ensure that students recognized what OARS were and were not. Following the approach of Brookfield (2012) to developing critical thinking, we taught students to "spot the OARS" (identifying the use of OARS as opposed to a "spot the error" approach, which would have focused on mistakes made in the MI session), hear what OARS sounded like, witness the usage and timing of OARS, examine the content of OARS, identify the tone used, and recognize the spirit of MI. 


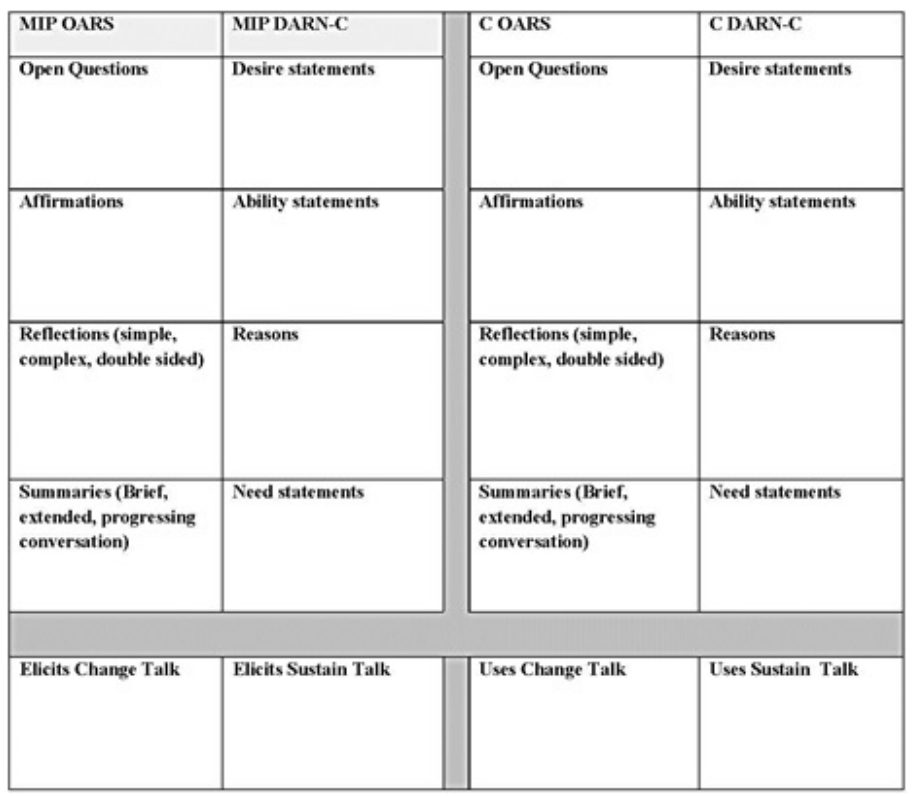

Figure 1

OARS - DARN-C-Change Talk/Sustain Talk Record Sheet. Instructions: Listen carefully and record the number of statements from the client and MIP.

We repeatedly used the case of the "Curious Smoker" from the second DVD Miller and partners (2013) to establish the definition of OARS in practice. Using an iterative process allowed us to discuss decisions made by the clinician based on the content of the conversation. During this process students were shown how to evaluate OARS within a coaching session by using a simple coding method (Figure 1) adapted from an exercise in the MINT Trainer's Manual (2008) This tool communicated one view of the $360^{\circ}$ process outlined above. The second view was produced by the "client" and the third view came from the MI Practitioner (MIP). We introduced the tool, explained its use and relevance to the content, explained the definition of MI ("a conversation about change;" Miller \& Rollnick, 2013, p. 12) and its measurable process, and conducted a practice session using the "Curious Smoker" case. Then the authors roleplayed and students used the tool as we conducted a "live" MSF feedback session. Following several practices with the video and the live demonstration, we perceived students were capable of "spotting the OARS" most of the time.

\section{PROFICIENCY LEARNING SESSION DESIGN}

The learning session design was based on Kolb's (1984) Experiential Learning Cycle (Figure 2). In the context of the class session students were continuously observing, assessing, knowing, judging, assimilating, accommodating, experimenting, and evaluating their experiences through the different role perspectives they had. Kolb's model, which emphasizes that "knowledge is continuously derived from and tested out in the experiences of the learner" (p. 27), was considered the best fit for this work because this model provides a deeper explanatory yield compared to other learning models (e.g., Lewin, 1951; Dewey, 1938). We perceived Kolb's model to permit student learning through a series of interactions between the personal, social, environmental and content influences affecting student cognition and emotional states before, during and after the learning experience.

During the "experience" phase the learner is exposed to a novel encounter or reinterpretation of a previous experience-in this case, role-

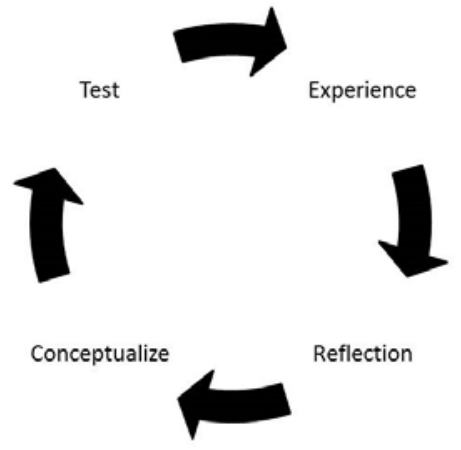

Figure 2

Kolb (1984) Experiential Learning Cycle

play for the practice of OARS. Following the role play, the students observing the role-play and the role-play participants conducted an open expressive "reflection" about what they observed in the interaction. This process was facilitated by the instructor and was conducted in two ways: 1) students discussed their evaluation of the person coaching (utilizing the tool shown in Figure 1) and 2) students posted a structured reflection on the online course management system. Lastly, students applied the new conceptual knowledge through role playing and tested their assumptions. The following class started with an examination of the posted reflections and an invitation to students to answer key questions like the following to explore their reflections on their experience: "Knowing what you know now, how do you see yourself applying OARS effectively?" and "What makes an effective reflection?" or "What "traps" could you step into when using OARS and how could you avoid them?"

The student learning outcomes permitted the learning to concentrate exclusively on providing what we believed to be a strong guided experiential learning process. We outline below the specific routine we used over a 4 week period to provide a six-hour supervised MI proficiency experience. Proficiency was evaluated against the understanding we had from the preparatory period outlined above and the use of the observation tool in Figure 1. We chose this depth of learning and this supervision model as a response to findings in studies by Miller and Mount (2001), Sholomskas and colleagues (2005), and Baer and colleagues (2004), who found that training sessions done in 1 or 2 day formats did not yield significant retention and skill acquisition and close supervision achieved improved learning outcomes.

\section{VIDEOTAPED ROLE PLAY}

We selected one activity from the MINT Resources for Training manual (2008) which would concentrate on OARS. During each practica session, the class was split into two groups of 12 students (Group A and Group B). Each group was given 1 hour and 15 minutes of interaction. While Group A worked with the teaching assistant in the practical session, Group B was engaged in new content presentation and discussion with the course instructor. At the conclusion of Group A's practical session, Group B would switch with Group A.

The role play was conducted using a "fish bowl" approach (Figure 3). One student would play the role of coach, another student the client, and two students were instructed to watch either the coach or the client. The remaining students were instructed to watch the coach-client interaction. The students were given observation forms and asked to document the frequency OARS. (Later in the course students were also asked to monitor 

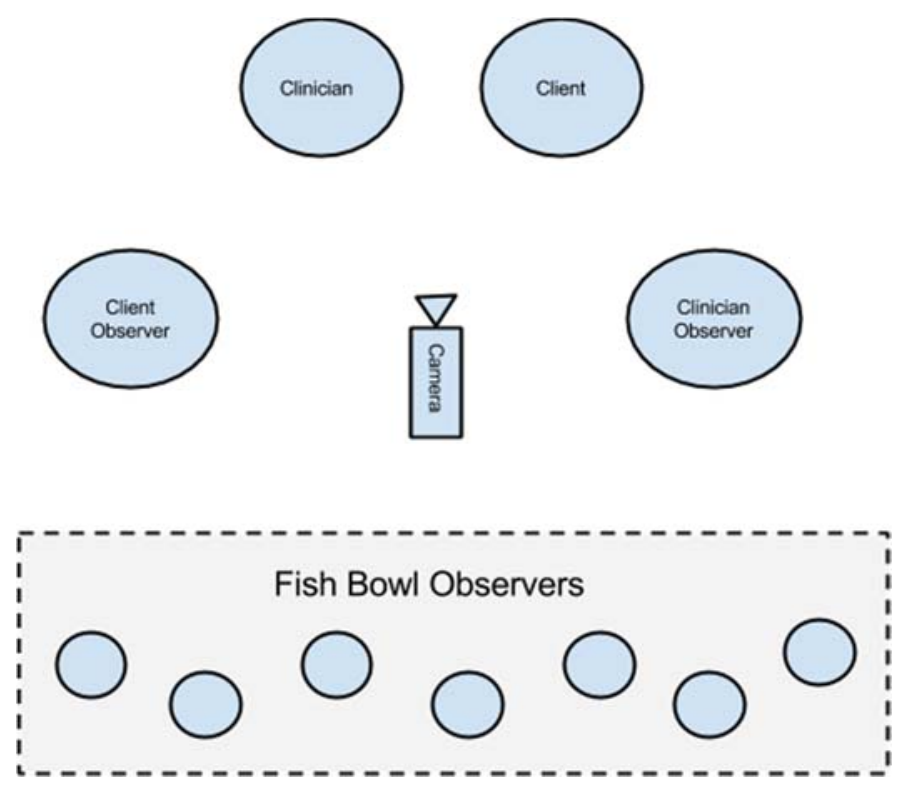

Figure 3

Fish bowl set-up

change talk, sustain talk, ability statements, and need statements in both the coach and the client.)

While the student role playing occurred, the coach-client interaction was video recorded for later use as a feedback opportunity for all students. For the first three sessions, students were asked to role play a client who wanted to make a behavior change. Students shaped their roles around known family's, friends', and personal behavior changes. The types of roles included smoking cessation, increasing physical activity, and decreasing stress. We chose this format because we wanted the students to be authentic in how they expressed themselves, felt and behaved. Most students in the client role defaulted to discussing a behavior change they were thinking of but had not started doing. The other student took on the "helper" role and what we achieved were conversations about change.

"Guest clients" were invited from the department's nutrition program to participate in the role plays for the final three sessions. The students who were invited were MI research students. The guest students used scenarios that the students may encounter in applied health setting like physical therapy or athletic training. We did this 1) to provide variance in the practice, 2) to introduce nutrition students from a different part of the department we work in to the course and 3) to provide relevant practice using contexts kinesiology students were looking forward to working in.

A single role playing session lasted approximately 15 minutes. Throughout the session, if coaches found themselves stuck in a situation, they could ask for a "timeout" when they could ask the instructor and student observers for guidance and reflections about the interaction.

After a 15 minute session, the group debriefed the interaction. The student role players (coach and client) and observers were asked questions such as: "What do you think went well?" and "What are your suggestions for future interactions?" A video replay of the interaction was incorporated in the debrief process.

\section{VIDEO REPLAY FEEDBACK SESSION}

All students participated in the video replay feedback session immediately following the interaction. This approach was adopted 1) to avoid guessing or trying to remember what happened in the interaction, 2) to discuss what actually took place instead of imaging what had taken place, 3) to maintain focus on facts, 4) to enable and coordinate group viewer interaction and feedback, and 5) to provide a facilitated reflection opportunity for the students that conducted the role play. This teaching rationale is supported by a meta-analysis by Fukkink, Trienekens and Kramer (2011) demonstrating that significant improvement in professional practice occurred after video feedback. Results suggested the earlier video feedback was given in an individual's professional career the stronger the uptake of preferred provider behavior was. Using structured observational strategies was found to be better for stronger learning retention and findings suggested that undergraduate students exposed to learning through video feedback would progress faster than graduate students. Research by Bialer, Kissane, Brown, Levin and Bylund (2011) demonstrated that the use of instant feedback following role plays including the client and the practitioner in highly emotive oncology consultation situations yielded high learning retention in medical professionals. Likewise, Roter and colleagues (2004) found in their study of communication training of medical residents that instant video feedback following a role play enabled greater learning and predicted significantly improved levels of empathy, reduced verbal dominance and use of open questions. A later investigation using focus group methodology by Nilsen and Baerheim (2005) showed medical students grew in self-esteem and confidence following video feedback after simulated consultations, despite their apprehension about the video feedback process at the beginning of their course of study.

The video replay was connected to a projector for ease of observation. The coach was given a self-assessment form and the remaining students were given a feedback form. Both forms ask students to score the clinician on a scale of 0 - 4 ( 0 being not present, 4 being present, frequent, and high quality) for OARS components and to offer comments as well.

Throughout the video replay feedback session, the instructor stopped the playback to debrief with the students about the situations which arose during the session. This was an opportunity for the group to participate in the structured reflective process outlined below. When the interaction was completed a brief break was taken and all the participants gathered in a circle. The students were briefed on the post-interaction debrief process. The instructor started by reminding the group what the purpose of the debriefing process was and that the tone should be respectful and understanding. The instructor asked the following questions to the MIP, client and group in turn:

> MIP: "What was your objective in the conversation?"

> MIP: "What went well for you in this exchange?"

> Client: "What did (name of student) do well as the MIP?"

> Group: "What did (name of student) do well as the MIP?"

$>$ MIP: "What do you hear you did well in this interaction?"

$>$ MIP: "What do you think you did not do as well as you would have liked?"

$>$ Client: "What do you think (name of student) might have been better at?"

$>$ Group: "What do you think (name of student) might have been better at?"

$>$ MIP: "Knowing what you know now, what solutions could you imagine using in the future if faced with this kind of situation again?"

$>$ Client: "Knowing what you know, what solutions might you use as the MIP in future?" 
$>$ Group: "Knowing what you know, what solutions might you use as the MIP in future?"

> MIP: "Having heard all the feedback, what steps can you take to continue to do what you do well and strengthen the things that have been identified to work on as a MIP?"

The process outlined here cannot be rushed and should be approached in an iterative way. It engages multiple voices and amplifies learning opportunities for all participants. The instructor used OARS to gain reflection and discussion points. When a particular point required deeper discussion it was framed as a "helpful" conversation. For example, a question like "How can this discussion be helpful to MIP's?" was used to ensure that the mindset of the group was positive and focused on helping student growth.

At the conclusion of the video replay feedback session the instructor collected the observation and video replay feedback forms. The collected observations and feedback were given to the student coach for review. Additionally, the video was posted to the online course management system for the student coach to review at his or her discretion.

\section{REFLECTIONS ON THE $360^{\circ}$ REVIEW PROCESS}

The $360^{\circ}$ review process was designed to enable intra-student, interstudent, and student-instructor reflection and feedback to flow smoothly. The students and instructors were well prepared to debrief the videotaped role plays, but the presence of the video recorder with a live feedback session created some anxiety in the class. Several students reported feeling nervous at the thought of their performance being recorded and evaluated. However, as predicted by Nilsen and Baerheim (2005), initial anxiety was overtaken by increased comfort with the process used to debrief and facilitate the discussion. We discuss in the recommendations below how feelings of anxiety experienced by student coaches were mitigated using a variety of instructional strategies.

\section{Instructional Strengths}

There were a number of perceived benefits and strengths in the use of this approach. Using the course outcomes to lead the design of the learning process enabled us to implement and evaluate student proficiency when practicing OARS in the context of a safe learning environment. Twenty four students participated in the course and none mentioned anxiety or worry in course feedback evaluations, In keeping with Nilsen and Baerheim (2005), students expressed an acceptance and comfort with the learning process. We perceived that anxiety was reduced because grades were not affected by student performance. The emphasis was on learning, not grade dependent performance outcomes.

\section{Instructional Weaknesses}

We did not conduct an experimental design to demonstrate the efficacy of the process, which would have been helpful in establishing instructional validity. Despite our preparation, when students switched from the didactic session to the practical phase we noticed that we should have checked the readiness of the students to participate in the practical session. We held a faulty assumption that most students (undergraduates in their last year of study) had prior experience providing peer feedback from previous classes or formal education. This led us to have to spend time unexpectedly defining feedback and its characteristics and instructing and demonstrating how to provide feedback. This took time from didactic and practical sessions, resulting in debriefing sessions sometimes being rushed and compressed compared to what we expected. Finally, we learned we should expect students to request coaching in all facets of MI proficiency in and out of the classroom.

\section{Ten Recommendations for Educators and Trainers}

We recommend the following actions be considered by trainers or educators developing interactive, MSF approaches for OARS skill acquisition.

1. Base education and training on an educational theory and use it to achieve the stated learning outcomes of the course of training.

2. Let the student learning outcomes lead the instructional learning design and concentrate effort on achieving them.

3. Match Ml content with specific practice and deliver it consistently especially with individuals with little $\mathrm{MI}$ experience. For example, focus on delivering didactic content about OARS and ensure the practice chosen is specific to the content taught.

4. Ensure that the instructional team is current with $\mathrm{MI}$ praxis and underlying theoretical literature and its relationship to the specific population being educated. We found the best ways to do this included a review of the following texts: Miller and Rollnick (2013); Rosengren (2009); Miller and associates (2008), attendance at the MINT Forum in Fort Wayne, Indiana in 2012; article reviews and repeated viewing of the DVD series explained earlier.

5. The instructional team should apply Kolb (1984) to their own experience because it provides a suitable educational theoretical framework for teachers or trainers to develop their classes or courses. We suggest course leaders meet before and after teaching students to reflect and apply lessons learned to the next learning session.

6. Prepare inexperienced experiential learners thoroughly. For example, show them what will happen with the video and feedback sessions, the equipment to be used, and how the session will be facilitated, and explicitly state that the room will be "safe" during the debrief when anxiety will ikely be the highest.

7. Use the MINT Trainers Manual (2008) to inspire the development of your own learning activities.

8. Use a systematic and structured debriefing process to achieve deep learning. This maintains reliability into the process and helps new experiential learners trust the learning process more.

9. Check the prior learning experiences of the individuals you are working with. Avoid making assumptions about the quality of their feedback or their capability to deliver it effectively.

10. Prepare to improvise and provide training on how to give feedback in the context of the learning context you are working in.

\section{CONCLUSION}

The purpose of this paper was to describe a teaching and learning process demonstrating how undergraduate students develop their use of OARS. We have shown how we constructed a theory led instructional design approach, explained how a 3600 review process worked with the use of video feedback. We intend our recommendations to assist educators and trainers design deep and rapid learning experiences. We believe we may have found an effective instructional process and intend to refine and test it based on achieved student learning outcomes.

\section{REFERENCES}

American Kinesiology Association (2014, April 16). Definition of Kinesiology. Retrieved from http:// http://www.americankinesiology.org

Anstiss, T. (2009). Motivational interviewing in primary care. Journal of Clinical Psychology in Medical Settings, 16(1), 87-93. 
Babenko-Mould, Y., Andrusyszyn, M. A., \& Goldenberg, D. (2004). Effects of computer-based clinical conferencing on nursing students' self-efficacy. The Journal of Nursing Education, 43(4), 149-155.

Baer, J. S., Rosengren, D. B., Dunn, C. W., Wells, E. A., Ogle, R. L., \& Hartzler, B. (2004). An evaluation of workshop training in motivational interviewing for addiction and mental health clinicians. Drug and Alcohol Dependence, 73 (1), 99-106

Beard, C. M., \& Wilson, J. P. (2006). Experiential learning: A best practice handbook for educators and trainers. Kogan Page Publishers.

Bialer, P. A., Kissane, D., Brown, R., Levin, T., \& Bylund, C. (2011). Responding to patient anger: development and evaluation of an oncology communication skills training module. Palliative and Supportive Care, 9(04), 359-365.

Brodie, D. A., \& Inoue, A. (2005). Motivational interviewing to promote physical activity for people with chronic heart failure. Journal of Advanced Nursing, 50(5), 518-527

Brookfield, S. (2012). Teaching for critical thinking. San Francisco: CA. JosseyBass.

Cantrell, M. A. (2008). The importance of debriefing in clinical simulations. Clinical Simulation in Nursing, 4(2), e19-e23.

Croffoot, C., Bray, K. K., Black, M. A., \& Koerber, A. (2010). Evaluating the effects of coaching to improve motivational interviewing skills of dental hygiene students. American Dental Hygienists Association, 84(2), 57-64.

Daeppen, J. B., Fortini, C., Bertholet, N., Bonvin, R., Berney, A., Michaud, P. A., ... \& Gaume, J. (2012). Training medical students to conduct motivational interviewing: a randomized controlled trial. Patient Education and Counseling, 87(3), 313-318

Dewey, J. (1938). Experience and education. New York: NY. Touchstone.

Fukkink, R. G., Trienekens, N., \& Kramer, L. J. (2011). Video feedback in education and training: Putting learning in the picture. Educational Psychology Review, 23(1), 45-63.

Haeseler, F., Fortin VI, A. H., Pfeiffer, C., Walters, C., \& Martino, S. (2011). Assessment of a motivational interviewing curriculum for year 3 medical students using a standardized patient case. Patient Education and Counseling, 84(1), 27-30.

Halpern, D. F. (1999). Teaching for critical thinking: Helping college students develop the skills and dispositions of a critical thinker. New Directions for Teaching and Learning, 1999(80), 69-74.

Hinz, J. G. (2010). Teaching dental students motivational interviewing techniques: Analysis of a third-year class assignment. Journal of Dental Education, 74(12), 1351-1356.

Koerber, A., Crawford, J., \& O'Connell, K. (2003). The effects of teaching dental students brief motivational interviewing for smoking-cessation counseling: a pilot study. Journal of Dental Education, 67(4), 439-447.

Kogan, J. R., Holmboe, E. S., \& Hauer, K. E. (2009). Tools for direct observation and assessment of clinical skills of medical trainees: A systematic review. JAMA, 302(12), 1316-1326.

Kolb, D. A. (1984). Experiential learning: Experience as the source of learning and development (Vol. 1). Englewood Cliffs, NJ: Prentice-Hall.

Lewin, K. (1951). Field theory in social sciences. New York: NY. Harper \& Row.

London, M., \& Smither, J. W. (1995). Can multi source feedback change perceptions of goal accomplishment, self-evaluations, and performancerelated outcomes? Theory-based applications and directions for research. Personnel Psychology, 48(4), 803-839.
Lundahl, B. W., Kunz, C., Brownell, C., Tollefson, D., \& Burke, B. L. (2010). A metaanalysis of motivational interviewing: Twenty-five years of empirical studies. Research on Social Work Practice, 20(2), 137-160.

Mariani, B., Cantrell, M. A., Meakim, C., Prieto, P., \& Dreifuerst, K. T. (2013). Structured debriefing and students' clinical judgment abilities in simulation. Clinical Simulation in Nursing, 9(5), e147-e155.

Matthews, R., \& Viens, D. C. (1988). Evaluating basic nursing skills through group video testing. The Journal of Nursing Education, 27(1), 44-46.

Miller, W. R., \& Mount, K. A. (2001). A small study of training in motivational interviewing: Does one workshop change clinician and client behavior? Behavioural and Cognitive Psychotherapy, 29 (4), 457-471.

Miller, R., Moyers, T. B., \& Rollnick, S. (Producers) (2013) Motivational Interviewing: Helping People Change. (DVD). United States.

Miller, W. R., \& Rollnick, S. (2009). Ten things that motivational interviewing is not. Behavioural and Cognitive Psychotherapy, 37 (2), 129.

Miller, W. R., \& Rollnick, S. (2013). Motivational interviewing: Helping people change. $3^{\text {rd }}$ Ed. New York: Guilford Press.

Morgeson, F. P., Mumford, T. V., \& Campion, M. A. (2005). Coming full circle: Using research and practice to address 27 questions about 360-degree feedback programs. Consulting Psychology Journal: Practice and Research, 57(3), 196.

Motivational Interviewing Network of Trainers (MINT) (2008). Trainer's Manual. Retrieved December 29, 2013 from http://www.motivationalinterview.org/Documents/TNT Manual Nov 08.pdf.

Nilsen, S., \& Baerheim, A. (2005). Feedback on video recorded consultations in medical teaching: Why students loathe and love it-a focus-group based qualitative study. BMC Medical Education, 5(1), 28.

Poirier, M. K., Clark, M. M., Cerhan, J. H., Pruthi, S., Geda, Y. E., \& Dale, L. C. (2004). Teaching motivational interviewing to first-year medical students to improve counseling skills in health behavior change. In Mayo Clinic Proceedings (Vol. 79, No. 3, pp. 327-331). Elsevier.

Resnicow, K., Dilorio, C., Soet, J. E., Borrelli, B., Hecht, J., \& Ernst, D. (2002). Motivational interviewing in health promotion: It sounds like something is changing. Health Psychology, 21(5), 444.

Rollnick, S., Miller, W. R., \& Butler, C. (2008). Motivational interviewing in health care: Helping patients change behavior. New York: Guilford Press.

Rollnick, S., Butler, C. C., Kinnersley, P., Gregory, J., \& Mash, B. (2010). COMPETENT NOVICE: Motivational interviewing. British Medical Journal, $340,1242-1245$.

Rosengren, D. B., Hartzler, B., Baer, J. S., Wells, E. A., \& Dunn, C. W. (2008). The video assessment of simulated encounters-revised (VASE-R): Reliability and validity of a revised measure of motivational interviewing skills. Drug and Allcohol Dependence, 97 (1), 130-138.

Rosengren, D. B. (2009). Building motivational interviewing skills: A practitioner workbook. Ne York: Guilford Press.

Roter, D. L., Larson, S., Shinitzky, H., Chernoff, R., Serwint, J. R., Adamo, G., \& Wissow, L. (2004). Use of an innovative video feedback technique to enhance communication skills training. Medical Education, 38(2), 145-157.

Sholomskas, D. E., Syracuse-Siewert, G., Rounsaville, B. J., Ball, S. A., Nuro, K. F., \& Carroll, K. M. (2005). We don't train in vain: A dissemination trial of three strategies of training clinicians in cognitive-behavioral therapy. Journal of Consulting and Clinical Psychology, 73 (1), 106. 
Söderlund, L. L., Madson, M. B., Rubak, S., \& Nilsen, P. (2011). A systematic review of motivational interviewing training for general health care practitioners. Patient Education and Counseling, 84(1), 16-26.

Weimer, M. (2002). Learner-centered teaching. San Francisco: Jossey-Bass.

White, L. L., Gazewood, J. D., \& Mounsey, A. L. (2007). Teaching students behavior change skills: Description and assessment of a new motivational interviewing curriculum. Medical Teacher, 29(4), e67-e71.

This work is licensed under a Creative Commons AttributionNoncommercial-No Derivative Works 30 United States License.

This journal is published by the University Library System of the University of Pittsburgh as part of its D-Scribe Digital Publishing Program, and is cosponsored by the Motivational Interviewing Network of Trainers. 